\title{
PENCIPTAAN TEATER BERDASARKAN KASUS MONEY POLITIC PADA PEMILU LEGISLATIF DI INDONESIA
}

\author{
Rano Sumarno \\ Institut Seni Indonesia Yogyakarta
}

\begin{abstract}
Abstrak: Legislatif Celeng merupakan hasil dari proses perancangan dan peciptaan karya naskah dan konsep pertunjukan teater. Kerja kreatif ini merupakan suatu kritik terhadap perilaku jahat para calon anggota legislatif yang menggunakan politik uang untuk menjadi seorang dewan. Penciptaan naskah dan karya teater ini merupakan kritik politik, dan bagian dari ikhtiar penyadaran bahaya money politic dalam bentuk kesenian. Metode psikologi seni Graham Wallas (1926) digunakan dalam proses penyusunan perancangan ini. Tahapan proses berfikir kreatif Wallas membantu penciptaan naskah drama beserta perancangan teater yang berjudul Legislatif Celeng. Tokoh-tokoh, plot naskah, dan semua material pelengkap dipadukan sehingga menghasilkan sebuah karya yang sesuai dengan kebutuhan pertunjukan.
\end{abstract}

Kata kunci: penciptaan teater, politik uang, kritik politik, naskah drama

\begin{abstract}
Legislatif Celeng is the result of designing and creation of theatre performance. This creative work is a criticism of the evil behavior of legislative council candidate who use money politics to become a council. The creation of the script and theatrical work constitutes political critics, and an effort to raise awareness of the dangers of money politics in the form of art. Graham Wallas' (1926) Art of Thought was used in the process of preparing this design. Stages of Wallas's creative thinking process helped in the creation of theatre scripts along with the theater design entitled Legislatif Celeng. Characters, script plots, and all supplementary materials are combined to produce a work that suits the performance needs.
\end{abstract}

Key words: theatre creation, money politics, political criticism, drama play

\section{Pendahuluan}

Penciptaan teater dengan judul
Legislatif Celeng (LENG)
adalah
perancangan pertunjukan teater dengan
tahapan penciptaan naskah disertai konsep
pertunjukannya. Kerja kreatif ini merupakan
kritik terhadap prilaku jahat para calon
anggota legislatif yang menggunakan
kekuatan uang demi memuluskan cita-
citanya menjadi anggota DPR, DPRD,
maupun DPD. Siasat Money politic kerap
dilakukan oleh calon legislator dengan
mengiming-imingi pemilih agar

memberikan hak suaranya dengan imbalan uang. Strategi ini biasanya dilakukan saat fajar menjelang hari pemilihan yang kemudian dikenal dengan istilah "serangan fajar", dengan target utama masyarakat golongan ekonomi rendah.

Berdasarkan sebuah analisis media yang dilakukan oleh lembaga Indonesia Indicator menjelaskan bahwa kasus terbanyak dalam pemilu legislatif tahun 2014 didominasi oleh praktik money politic yakni sebesar $52 \%$ dengan pemberitaan sebanyak 1.716 berita (ekspose) yang 
disoroti oleh media massa. Analisis tersebut dilakukan secara real time dengan cakupan 292 media online Nasional dan daerah seperti terlihat dalam bagan berikut ini:

\begin{tabular}{|c|c|c|c|}
\hline No & Jenis Pelanggaran & $\begin{array}{c}\text { Jumlah } \\
\text { Ekspose } \\
\text { Media } \\
\end{array}$ & $\%$ \\
\hline 1 & Money Politic & $\begin{array}{l}1.716 \\
\text { media }\end{array}$ & 51,97 \\
\hline 2 & $\begin{array}{l}\text { Penggelembungan } \\
\text { suara }\end{array}$ & $\begin{array}{l}593 \\
\text { media }\end{array}$ & 17,85 \\
\hline 3 & Pencoblosan ulang & $\begin{array}{l}393 \\
\text { media }\end{array}$ & 11,83 \\
\hline 4 & $\begin{array}{l}\text { Pelanggaran kode } \\
\text { etik }\end{array}$ & $\begin{array}{l}315 \\
\text { media }\end{array}$ & 9,48 \\
\hline 5 & $\begin{array}{l}\text { Penghitungan } \\
\text { ulang }\end{array}$ & $\begin{array}{l}304 \\
\text { media }\end{array}$ & 9,15 \\
\hline
\end{tabular}

Tabel 1. Jumlah pelanggaran (sumber: Indonesia Indicator (Mei 2014)

Analisis tersebut mengungkapkan bahwa kasus money politic telah menjadi pembahasan utama media massa di seluruh provinsi di Indonesia. Provinsi yang paling tinggi angka ekspose media untuk kasus money politic adalah; Sumatra Barat, Riau, Bengkulu, Lampung, Jawa Barat, Jawa Timur, dan Papua. Sementara data dari divisi humas Mabes Polri menjelaskan bahwa kasus politik uang yang masuk terbanyak adalah dari Sulawesi tengah (10 kasus), Bengkulu (8 kasus), NTT (7 kasus), Gorontalo (6 kasus), Jawa Tengah (5 kasus), Sulawesi Selatan (5 kasus), Sulawesi Utara (3 kasus), Maluku (3 kasus), dan Bali (2 media), sementara daerah sisanya adalah rata-rata masuk satu kasus.

Pesta demokrasi Indonesia semestinya dapat berjalan secara bersih, jujur dan adil sesuai dengan slogan pemilu yang selalu disuarakan pemerintah melalui komisi pemilihan umum (KPU). Namun pada kenyataannya jauh pangang dari api, praktik money politic seperti mengakar dan menjadi tradisi tersendiri hingga lembaga badan pengawas pemilu (bawaslu) dibuat kewalahan dalam penanganannya. Para caleg seakan berlomba dan adu kekayaan untuk saling mengambil hati pemilih dengan cara menjatuhkan lawan politiknya.

Pasal 73 ayat 1 dan 2 undang-undang pemilu menjelaskah bahwa: calon dan atau tim kampanye dilarang menjanjikan dan atau memberi uang atau materi lainnya untuk mempengaruhi penyelenggara pemilihan dan atau pemilih. Calon yang terbukti melakukan pelanggaran tersebut berdasarkan putusan bawaslu dapat dikenakan sanksi pembatalan paslon oleh KPU provinsi / KPU kabupaten kota. Meski peraturan tentang money politic telah diatur secara gamblang dalam undang-undang pemilu, namun para peserta pemilu seakan tidak peduli dan mengabaikan ancaman pidana dari tindakannya tersebut. Sangsi bagi pelaku kejahatan pemilu sendiri diatur dalam pasal 178 undang-undang pemilu poin A sampai dengan D.

Dengan semakin buruknya budaya money politic dalam pemilu di Indonesia, perlu sebuah gerakan penyadaran akan bahaya dari akibat yang ditimbulkan baik terhadap peserta pemilu maupun terhadap masyarakat sebagai pemilihnya. Money politic sangat berbahaya dalam membangun proses demokrasi yang bersih di Indonesia, karenanya prilaku tersebut dapat dikategorikan sebagai sebuah tindakan kejahatan, karena; money politic adalah sebuah pelecean demokrasi sekaligus pembodohan masal terhadap rakyat kecil. Money politic juga merupakan jebakan bagi rakyat yang memilihnya, karena setelah pelaku terpilih menjadi anggota legislatif tidak ada lagi ikatan janji dalam kampanyenya karena merasa semua telah diselesaikan dengan uang bayaran. Bahaya lain dari money politic adalah matinya kaderisasi politik di Indonesia, dimana setiap legislator telah memiliki pemilih tetap yang bisa dibayar setiap lima tahunnya, 
akibatnya anggota dewan dari periode keperiode hanya diisi oleh itu-itu saja, sehingga tidak ada harapan dalam sebuah perubahan. Bahaya yang lebih fatalnya lagi adalah pelaku money politic cenderung akan melakukan korupsi karena yang pertamakali difikirkan setelah terpilih adalah kembali modal dengan cara apapun.

Merespon dari pemikiran tersebut diatas, maka penciptaan teater dengan judul LENG ini adalah bagian dari ikhtiar penyadaran bahaya money politic dalam bentuk seni pertunjukan. Legislatif celeng merupakan penggambaran sosok pejabat legislatif yang rakus pada kekuasaan serta tidak memperdulikan penderitaan orang lain atas kebijakan-kebijakan yang diambilnya. Celeng adalah sosok binatang kotor yang hidup di hutan, jenis hewan omnivora ini bahkan memakan bangkai untuk memenuhi kebutuhan hidupnya. Pada daerah tertentu hewan ini sering dikaitkan dengan mitos perklenikan. Legislatif celeng pada judul nasah ini bisa diartikan sebagai pejabat legislatif yang rakus kekuasaan, dan menggunakan cara-cara kotor demi memuluskan keinginannya.

Penciptaan Legislatif Celeng merujuk pada rumusan yang menghadirkan beberapa pertanyaan sebagai berikut: 1). Bagaimanakah bentuk naskah Legislatif Celeng dengan gaya surealis? 2). Bagaimanakah proses penciptaan yang ditempuh dalam menyusun naskah Legislatif Celeng?

\section{Tinjauan Pustaka}

Penciptaan naskah dan perancangan konsep pertunjukan Legislatif Celeng ini akan dibawakan dalam bentuk teater surealis. Seperti adegan pertemuan Baleng dengan Nyikembang, dimana pertemuan dua dunia yang berbeda itu menjadi bersenyawa seperti khasnya dalam teater super realis. Adegan lain yang terasa kental bentuk surealisnya adalah pecakapan Baleng dengan arwah Neng Ratu, persetubuhan Baleng dengan Nyi Kembang, dan lain lain.

Super realisme atau surealisme merupakan reaksi dan perlawanan terhadap rasionalisme. Gerakan surealisme adalah aliran dimana seniman membebaskan dirinya dari kontrol kesadaran dunia. Unsur kejutan serta ketidaklaziman merupakan kekuatan unik yang dimiliki oleh aliran ini. Tumpang tindih dua dunia yang saling berlawanan hadir bersamaan tanpa ada selaput yang membatasinya.

Surealisme pada awalnya adalah gerakan dari sastra. Istilah ini dikemukakan Apollinaire untuk dramanya tahun 1917. Dua tahun kemudian Andre Breton mengambilnya untuk menyebut eksperimennya dalam metode penulisan yang spontan. Gerakan dipengaruhi oleh teori psikologi dan psiko analisis sigmun Freud. Karya surealisme memiliki unsur kejutan, tidak terduga, ditempatkan berdekatan satu sama lain tanpa alasan yang jelas (Susanto, 2012).

Gerakan surealisme muncul sebagai reaksi seniman atas kekecawaan pada meletusnya perang dunia pertama. Menyaksikan kenyataan dunia yang porak poranda oleh peperangan mendorong para pelaku seni saat itu tidak bisa lagi berfikir secara rasional. Kenyataan saling bertumpang tindih dengan dunia imaji yang tidak terbatas.

\section{Metode}

Damajanti menjelaskan bahwa Psikologi seni merupakan bagian dari ilmu psikologi yang memfokuskan diri pada pertanyaan-pertanyaan yang berkaitan dengan para pendukung dalam proses artistik, yaitu seniman, pengamat, dan kritikus (2006). Pertanyaan studi psikologi terhadap seniman dan pengamat seni memberikan kerangka berfikir dalam memahami psikologi, seperti; apa yang mendorong seniman untuk mencipta? Proses kognitif apa yang terlibat dalam kreasi artistik? Apa yang mendorong manusia untuk mengapresiasi karya 
seni? Dan kemampuan kognitif apa yang dibutuhkan untuk memahami karya seni? Kerangka berfikir tersebut sebenarnya telah muncul sejak masa Yunani kuno, dimana Plato menyatakan bahwa penyair dirasuki oleh inspirasi yang hebat dan proses kreasi adalah satu kondisi dimana fakultas kesadaran penyair menyerah pada kegilaan. Pandangan Plato bertolak belakang dengan Aristoteles yang menyatakan bahwa kreasi seni merupakan keterlibatan keahlian yang terkendali, cermat, dan penuh ketelitian. Perbedaan sudut sudut pandang ini selanjutnya membentuk pandangan tentang proses kreasi artistik pada zaman-zaman berikutnya. (Damajanti, 2006).

Dalam proses kreatifnya, penciptaan Legislatif Celeng menggunakan metode psikologi seni dengan penjabaran sebagai berikut:

a. Tahap preparation (tahap persiapan atau masukan) adalah langkah awal dimana pencipta melakukan persiapan dengan melakukan inventarisasi data dan fakta. Berbagai dokumentasi baik berupa liputan media; Koran, televisi, maupun media online di inventarisir sebagai bahan pertimbangan dalam melakukan langkah-langkah proses kreatif penulisan. Upaya dalam pengkayaan data juga dilakukan dengan melakukan interaksi berupa diskusi dengan pihak-pihak tertentu. Menginventarisasi naskah-naskah drama dengan aneka bentuk, gaya, dan aliran, juga merupakan tahapan persiapan yang dilakukan untuk pengkayaan bahan referensi penulis. Sebagai upaya pemetaan, pada tahapan ini juga dilakukan penginventarisasian naskah-naskah yang memiliki kesamaan topik tentang pemilu dan pesta demokrasi. Pemilihan bentuk dan gaya naskah yang tepat akan menghasilkan karya yang berkualitas. Fenomena maraknya money politic telah menjadi isu Nasional dengan latar belakang masalah kejahatan demokrasi. Diperlukan ketepatan dalam memilih bentuk dan gaya naskah agar manfaat dan tujuan dari penciptaa naskah ini dapat tercapai dengan maksimal, serta pesan yang terkandung didalamnya lebih mudah tersampaikan.

b. Tahap incubation adalah proses berfikir dengan alam bawah sadar, dimana pencipta untuk sementara waktu "mengerami" capaian yang telah didapat, artinya kegiatan mencari dan menginventarisasi informasi tidak lagi dilanjutkan. Pada tahapan ini pencipta lebih banyak melakukan meditasi atau pencarian inspirasi dengan melakukan proses kreativitas yang lain. Proses kreatif yang dilakukan adalah dengan melakukan apresiasi teater -baik naskah maupuan pertunjukanyang memiliki kemiripan dengan masalah yang akan diciptakan. Kemiripan tersebut bisa meliputi tema, bentuk, latar cerita, gaya, dll.

c. Tahap illumination merupakan bagian terpenting dalam proses penciptaan ini. Pada titik ini pencipta kembali dalam kesadarannya melakukan proses kreatif mencipta Legislatif Celeng. Hasil kreatifitas yang telah dikumpulkan kembali dibuka untuk dirajut menjadi karya seni yang diharapkan. Pada saat mencipta, penulis melakukan eksplorasi dari data-data yang dimiliki dengan pengalaman dan wawasan apresiasi pada saat meditasi. Inspirasi dan gagasan-gagasan baru yang muncul dikembangkan menjadi naskah utuh setengah jadi. Setelah naskah (setengah jadi) tersusun, selanjutnya pencipta melakukan komunikasi dengan para pelaku teater untuk melakukan reading naskah. Pada tahapan ini akan terjadi timbal balik gagasan dan pandangan dari para pembaca naskah sehingga hasil yang telah dicapai dapat lebih disempurnakan lagi. Langkah terakhir dari tahapan ini adalah penyempurnaan karya sehingga naskah yang diciptakan menempuh titik akhir berupa karya jadi dan siap untuk dipublikasikan.

d. Tahap verification adalah ajang uji karya. Tahapan ini sekaligus untuk mengevaluasi karya tersebut terhadap realitas. pementasan dapat berupa pertunjukan teater atau dramatic reading yang dilanjutkan dengan diskusi hasil penemuan tersebut dengan audience pertunjukan.

\section{Hasil dan Pembahasan}

Sinopsis

Alkisah seorang aktifis buruh pabrik bernama Baleng sangat berambisi untuk bisa menjadi anggota legislatif. Dukungan dan kepercayaan dari para buruh untuk 
menunjuk dirinya sebagai pimpinan serikat menjadikannya termotifasi kuat untuk ikut bersaing dalam perebutan kursi di pemilu. Namun apadaya kekuatan masa tidak berarti apa-apa tanpa didukung modal rupiah yang besar. Baleng ditolak menjadi caleg oleh partai-parrtai yang ditemuinya karena tidak mampu membayar mahar politik yang menjadi persyaratannya.

Untuk memenuhi ambisinya, Baleng mengambil jalan pintas dengan terjun kedunia klenik. Mempersembahkan jiwaraga kepada Nyi Kembang sebagai penguasa goa suci dipesisir pantai Nusakambangan. Menempuh kekayaan dengan cara ngepet ditentang keras oleh sang istri (Ratu), namun karena tekad keras Baleng untuk bisa bersaing di Pileg akhirnya Neng Ratu harus merelakan dirinya bersuami seorang penyembah siluman. Penderitaan Neng Ratu berakhir dengan tragis karena Nyi Kembang meminta Baleng untuk menumbalkan istrinya.

Pengorbanan Baleng hingga harus membunuh sang istri tercinta akhirnya menemukan balasan yang setimpal, tiba-tiba kekayaannya melimpah dan gepokan uang dengan mudah didapat. Dengan modal kekayaannya itu Baleng kembali melanjutkan ambisinya untuk nyaleg dalam pemilu. Mahar yang besar dikeluarkan hingga akhirnya Baleng masuk dalam daftar calon legislatif disalah satu partai penguasa. Siasat uangpun mulai dilancarkan, Baleng membayar jajaran pengurus partai hingga para konstituen agar dirinya mendapatkan keistimewaan dalam pencalonannya. Baleng membentuk tim sukses dengan segala kemewahannya, uang mulai disebarkan sebagai senjata pencitraan kepada masyarakat pemilihnya, hingga akhirnya Baleng benar-benar terpilih menjadi anggota legislatif. Keberhasilan Baleng menjadi anggota dewan berlanjut dengan dinobatkan dirinya sebagai ketua fraksi sekaligus ketua dewan pimpinan wilayah, tentu saja jabatan itu dia beli dengan mahar polittik yang mahal juga.

Kekayaan dan kekuasaan melekat erat dalam kehidupan Baleng saat ini, namun ada kerinduan pada sosok istri yang dulu sangat dicintainya. Setiap Baleng mengingat Neng Ratu, hatinya teriris karena terikat sumpah yang hanya akan memberikan jiwa raga dan cinta kepada Nyi Kembang. Setiap malam jumat Baleng melakukan ritual cinta dengan memberikan kelaki-lakiannya kepada Nyi kembang. Pergumulan birahi itu adalah kenikmatan bagi Nyi Kembang, namun kesakitan yang teramat dalam bagi Baleng.

Suatu hari ketika Baleng meresmikan desa wisata disebuah kampung pedalaman, kesetiaannya pada Nyi Kembang tergoncang, mata dan hati Baleng luluh oleh kecantikan seorang penari yang wajahnya mirip dengan Neng Ratu, Baleng kembali jatuh cinta, bahkan dayung bersambut hingga keduanya menjalani hubungan yang istimewa. Disuatu tempat ketika mereka tidak lagi bisa mengendalikan hasrat cintanya, Nyi Kembang datang dengan kemurkaan. Dibawanya beberapa prajurit untuk menyeret Baleng dan membunuh si penari cantik itu. Nyi Kebang tidak bisa lagi menahan kemarahannya, dicabut kembali segala kekuatan, dan diambil kembali seluruh kemewahan yang pernah diberikan. Baleng kesakitan, seluruh hartanya lenyap, yang tersisa hanya bau menyengat serta luka borok disekujur tubuhnya. Baleng merangkak menuju benjolan tanah tempat dimana dulu dia menguburkan istrinya. Air mata tertumpah dalam penyesalan yang teramat. Lalu akhirnya Baleng menyusul sang istri menuju kedamaian abadi.

\section{Struktur Naskah}

Setiap karya sastra memiliki unsur yang berbeda. Unsur-unsur naskah drama diantaranya adalah; tema, dialog, peristiwa, latar (setting), character (penokohan), alur, premise (plot), dan gaya bahasa. 
a. Tema

Tema adalah gagasan yang hendak dikomunikasikan pencipta karya seni terhadap khalayak. Tema bisa saja menyangkut masalah sosial, budaya, religi, pendidikan, politik, pembangunan, dan sebagainya (Bahari, 2008). Tema merupakan pokok pikiran atau ide dasar cerita yang berfungsi sebagai pedoman dan arah kerja. Prilaku jahat para calon legislator yang menggunakan kekuatan uang sebagai upaya pemenangannya dalam pemilu menjadikan pertunjukan ini merujuk pada sebuah tema yaitu "money politic sebagai kejahatan demokrasi”.

Penggambaran tema dapat dilihat dari dialog berikut ini yang disampaikan oleh tokoh Sarkim dan Baleng seperti berikut :

1. Sarkim : Hahaha., haha.., kamu pikir partai ini punya siapa Leng? Hah? Punya nenekmu? Atau punya kakekku? Hahaha., Partai ini dibangun pake duit. Dirawat dan digedein pake duit. Kalau kamu mau cari duit dipartai ini, cintai dulu pake duitmu. Logikanya kalau kamu ngidupin partai ini, maka partai akan ngasih kehidupan buat kamu.

2. Baleng : Tapi pencalonan saya tidak semata-mata untuk cari duit Pak.

3. Sarkim : Lalu cari apa? Hahaha., cari apa lagi kalau bukan cari duit? Hahaha. jangan munafik Leng.

4. Baleng : Dibelakang saya ada ribuan buruh yang siap memenangkan agar saya bisa lolos jadi anggota Dewan.

5. Sarkim : Terus ?

6. Baleng : Saya hanya ingin menyalurkan suara para buruh agar nasibnya bisa lebih terjamin.

7. Sarkim : Terus ?

8. Baleng : Saya tau saya orang miskin yang tidak punya modal buat nyaleg, tapi Please, masukan saya sebagai calon di partai ini. Saya jamin saya akan terpilh sebagai anggota dewan.

9. Sarkim : Ahahaha.., Ribuan orang yang lamar nyaleg kemarin semua ngomongnya kaya gitu Leng. Ada yang bilang punya masa santri di pondoknya, ada yang bilang punya karyawan di perusahaannya, macem-macem. Tapi semuanya jeblog. Partai ini butuh kepastian bukan impian.

10. Baleg : Tapi ini nyata pak, para buruh yang tergabung dalam asosiasi pekerja di kota ini sudah mendeklarasikan dukungannya dan siap memenangkan pencalonan saya.

11. Sarkim : Ahahaha.., coba difikir Leng. Kebutuhan kampanye: bendera partai, poster partai, kaos partai, iklan partai, transfortasi, konsumsi, akomodasi, lobyloby politik, itu biayanya mau dari mana? Ha? Jangan mimpi Leng, ingat kata pepatah "gak ada makan siang gratis" itu artinya bayar., bayar. Hahaha., Hahaha.. (Sosok Sarkim menghilang)

12. Baleng : (Lemas tak bergairah) Apa ada jalan lain?

\section{b. Latar / setting}

Setting merupakan tiga unsur pertunjukan teater yang mampu menunjukan keterangan tempat, waktu dan latar sosial (Nurgiyantoro, 2005). Setidaknya setting dapat menggambarkan beberapa hal yang berkaitan dengan latar tempat, latar waktu, dan latar sosial. Lakon Leng mengambil latar tempat di perkotaan, dengan latar waktu kekinian, dan menggambarkan latar sosial masyarakat buruh pabrik dan masyarakat desa dengan taraf hidup yang sederhana. Hal tersebut dapat kita lihat dari dialog berikut ini:

45. Sutet : Sssstt.. (sedikit berbisik) pasti ada jalan.

46. Baleng : Kemana?

47. Sutet : Nyi Kembang

48. Baleng : Dimana?

49. Sutet : Di Goa suci, pantai selatan.

50. Baleng : Caranya?

51. Sutet : Mengabdi dan berserah diri

52. Baleng: (Antusias) Terus ?

53. Sutet : Hehehe.., terus kamu nikmati apa yang kamu mau.

54. Baleng : Modal ?

55. Sutet : Lebih dari itu. 
56. Baleng : (Lebih antusias) jadi anggota dewan?

57. Sutet : Lebih tinggi lagi

58. Baleng : (Lebih antusias lagi) Saya mau. (Alunan musik behenti)

59. Sutet : Hehehehe, ikut saya

Latar tempat tidak menyebutkan identitas daerah, untuk menjaga sensitifitas dan menghindari tuduhan kepada para calon legislatif yang sedang berkompetisi. Namun meski dalam pertunjukan ini tidak secara gamblang dijelaskan latar tempatnya, dari beberapa adegan bisa menggambarkan strata masyarakat yang terjadi pada lakon sebagai berikut:

170. Pak RT : Ehh sabar-sabarsabar..

171. Neneng : Dasar orang sinting gak punya pikiran

172. Pak RT : Iya sabar dulu Bu Neneng, ini ada apa? Tolong ceritakan dengan rinci kejadiannya.

173. Neneng : Saya lagi rebahan di rumah pak RT

174. Pak RT : Looh koq rebahan di rumah saya ??

175. Warga: Woooo maksudnya Bu Neneng rebahan dirumahnya, Pak RT

176. Pak RT : Ooohhh, lah terus ??

177. Neneng : Tiba-tiba dia menusuk pantat saya pake paku, sakit banget Pak RT

178. Pak RT : Waduuuh kurang ajar, eh coba liat pantatnya ??

179. Warga:Woooo bukan muhrim dong Pak RT

180. Pak RT : Hehehe maksud saya koq bisa dia ada di rumah Bu Neneng ??

181. Neneng : Dia masuk diam-diam lewat jendela rumah, dasar sinting.

182. Pak RT : Sebentar saya Tanya dulu ya. (kepada orang gila, sambil marah) Hey kamu orang gila, benar kamu sudah menusuk pantat $\mathrm{Bu}$ Neneng pake paku??

183. Pepeng : Hehehehe Iyaaa coblossss
184. Pak RT : Kurang ajar, pantat $\mathrm{Bu}$ Neneng kulitnya putih atu item??

185. Warga: Wooooo, ngapain Tanya yang itu sih???

Dialog kedua tokoh diatas terjadi pada saat Baleng hampir putus asa karena tidak punya modal untuk nyaleg, namun mendapat pencerahan dari tokoh Sutet untuk mengabdi di Goa Suci pantai selatan. Penyebutan tempat tersebut merujuk pada sebuah lokasi pesugihan yang terletak di pesisir pantai selatan jawa tengah, tepatnya daerah Nusakambangan.

Gambaran yang menjeaskan latar waktu dari pertunjukan ini bisa kita simak dari adegan sebagai berikut:

1. Dirijen KPU : Tu, wa, ga.

2. KPU : (Mars pemilu era Orde Baru) "Pemilihan umum telah memanggil kita Sluruh rakyat menyambut gembira Hak demokrasi pancasila Hikmah Indonesia merdeka Pilihlah wakilmu yang dapat dipercaya Pengemban ampere yang setia Dibawah undang-undang dasar 45 Kita menuju ke pemilihan umum"

3. Seseorang : (Datang meniup peluit) Priittttt., Wuuuhh jadul. Itu lagu jaman orde baru. Yang era reformasi dong! Milenial gitu loh (pergi).

4. Dirijen KPU : (sempat bingung) Ayo ayo yang era reformasi

5. KPU : (Mars pemilu era Reformasi) Pemilihan umum kini menyapa kita Ayo songsong dengan gembira. Kita pilih wakil rakyat anggota DPR, DPD, dan DPRD

6. Dirijen KPU : Stop stop, eh jangan lupa di-record terus unggah di medsos: WA, IG, Facebook, Youtube, dll. Ayo ayo ulangi. Tu wa ga...

Dialog adegan diatas secara jelas menunjukan keterangan waktu yang menyebutkan jaman milenial dan sudah maraknya medsos seperti WA (whatsapp), IG (instagram), FB (facebook), Youtube, dll. Keterangan tersebut bisa kita simpulkan 
bahwa latar waktu yang terjadi pada pertunjukan tersebut adalah kekinian.

c. Plot

Premise / Plot merupakan rumusan intisari cerita sebagai landasan ideal dalam menentukan arah tujun cerita (Harymawan, 1993), wujudnya adalah berupa jalinan peristiwa yang ditandai dengan sebab dan akibat. Kepaduan alur dalam karya sastra diwujudkan oleh hubungan tokoh dan temanya. Terdapat beberapa bentuk alur, seperti: alur maju, alur mundur, dan alur campuran. Plot disusun dari beberapa insiden berkaitan dengan watak. Kepastian panjangnya plot dan batasan-batasannya dalam susunan dramatik dan penangkapan panca indra bukanlah teori artistik, melainkan didasarkan pada drama itu sendiri. Kontruksi plot yang bagus tentu harus menyesuaikan diri dengan prinsipprinsip ini (Anwar, 2004:10). Alur yang digunakan dalam naskah Leng ini menggunakan alur campuran, di mana tokoh-tokoh mengalami kenaikan konflik namun terjadi flashback di beberapa adegan yang terjadi. Sisipan-sisipan adegan flashback dikemas menjadi adegan surealis berupa bayangan yang diciptakan menjadi adegan seolah nyata. Sebagian contoh dari adegan ini adalah sebagai berikut:

Adegan: "Amarah Baleng terbakar, lalu menampat pipi Ratu. Perempuan itu terduduk dan menatap Baleng dengan sorotan mata yang teramat dalam."

29. Baleng: (Menahan Emosi) Cara iblis ataupun cara Tuhan, aku tidak peduli lagi Ratu.

30. Ratu : (Nafasnya dalam, air matanya keluar) Belum kakimu menginjak disana, tapi matamu sudah gelap. Bahkan kamu sudah lupa siapa perempuan yang sedang kamu hadapi ini Baleng.

31. Baleng: (Membuang amarah) Aaaarrrggh
32. Ratu : (Sejenak hening, hanya terdengar suara nafas berat mereka) siapa yang membawamu sampai sejauh ini Leng?

Adegan: "Baleng menatap ke langit-langit rumah, matanya kosong, fikirannya menerawang, dalam ingatannya muncul sosok sarkim, seorang pimpinan partai."

33. Sarkim: Hahaha., haha.., kamu pikir partai ini punya siapa Leng? Hah?

Punya nenekmu? Atau punya kakekku? Hahaha., Partai ini dibangun pake duit. Dirawat dan digedein pake duit. Kalau kamu mau cari duit dipartai ini, cintai dulu pake duitmu. Logikanya kalau kamu ngidupin partai ini, maka partai akan ngasih kehidupan buat kamu.

34. Baleng: Tapi pencalonan saya tidak semata-mata untuk cari duit Pak.

35. Sarkim: Lalu cari apa? Hahaha., cari apa lagi kalau bukan cari duit? Hahaha. jangan munafik Leng.

36. Baleng: Dibelakang saya ada ribuan buruh yang siap memenangkan agar saya bisa lolos jadi anggota Dewan.

37. Sarkim: Terus ?

38. Baleng: Saya hanya ingin menyalurkan suara para buruh agar nasibnya bisa lebih terjamin.

\section{d. Gaya Bahasa}

Gaya bahasa dalam sebuah karya sastra merupakan cara khas yang digunakan pencipta dalam mengemukakan gagasan, pikiran, dan perasaan. Gaya bahasa juga merupakan cara penulis dalam menggunakan bahasa untuk menimbulkan kesan-kesan tertentu dan digunakan untuk melahirkan keindahan. Pertunjukan Leng memilih gaya bahasa Indonesia yang biasa digunakan oleh golongan masyarakat menengah kebawah. Latar belakang karyawan pabrik melahirkan gaya bahasa realis. Pilihan bahasa yang digunakan oleh 
tokoh-tokoh dalam pertunjukan ini banyak menggunakan kata-kata keseharian. Berikut adalah gambaran gaya bahasa yang digunakan dalam pertunjukan Leng :

138. Timses Baleng : Hey kalian tim sukses ya?

139. Semua Timses : Iya

140. Timses Baleng : Timsesnya siapa??

141. Timses 1 : Nih, Dr. Sungaeb Wijaksono, S.Pd

142. Timses 2 : Iing mathobi'i mustofa Sarjana Agama

143. Timses 3 : Kalo saya timsesnya Anwar Saepuloh, $\mathrm{PhD}$

144. Timses 4 : Haji Atit

145. Timses Baleng : Hehehe kalian ngebagi amplop, terus kalian sendiri dapat bayaran berapa??

146. Timses 2 : Iing mathobi'i mustofa Sarjana Agama adalah pengusaha muda yang sukses dibidang property satu amplop isinya 50 ribu, dan saya dibayar 500 ribu

147. Timses 1 : Hahaha, pengusaha koq Cuma ngegajih 500 ribu, Nih Dr. Sungaeb Wijaksono, S.Pd bukan pengusaha tp timsesnya dibayar 1 juta

148. Timses $3 \quad$ : Hehehe memang jagoan-jagoan kalian itu bukan levelnya Anwar Saepuloh, PhD yang kuliahnya aja di luar negeri pulang pergi numpak pesawat udara. Bayarannya pake dolar Amerika, saya digaji 10 dolar.

149. Timses $1 \quad$ : Woo dasar kampung, 1 dolar itu harganya 15 ribu, jadi kalo 10 dolar ya Cuma 150 ribu.

150. Timses $3 \quad$ : Weeehh, waduh iya pa yah?? We alah.. Cuma 150 ribu to gajiku??

151. Timses 4 : Cuma pada dibayar pake uang kok ya pada bangga. Nih jagoan saya Haji Atit mau gaji saya pake 1 ekor anak sapi yang baru disapih dari mbok nya, tapi katanya syaratnya Haji Atit harus menang dan lolos jadi anggota dewan.

152. Timses 2 : Lah terus kalo kalah?

153. Timses 4 : Ya nggak jadi anak sapinya.
154. Timses 2 : Wooo lah ya mau maunya.

155. Timses Baleng : Husss udah udah., hey dengerin ya, sekarang saya ganti semua gaji dari bos kalian berlipat-lipat (memberikan amplop tebal berisi uang) nih masing-masing dapat 5 juta.

156. Semua Timses : (Senang dan kaget) Hahh 5 juta???

157. Timses Baleng : Mau Nggak ???

158.Semua Timses : Mau mau mau

\section{e. Tokoh}

Tokoh adalah bahan yang paling aktif yang menjadi penggerak cerita. Character disini adalah tokoh yang hidup, dia bukan boneka. Melalui tokoh akan Nampak peristiwa-peristiwa yang muncul dan hadir baik penyampaiannya melalui dialog maupun tubuh fisik. Tokoh adalah bahan yang paling aktif menjadi penggerak jalannya cerita. Terdapat dua macam watak atau sifat manusia dalam berhubungan, yakni dengan dunia luar ataupun dengan sesama manusia (Harymawan, 1993). Karya drama termasuk salah satu genre sastra disamping novel, cerpen, dan puisi. Teks drama sebagai gejala kesenian dapat dianggap mencerminkan kenyataan sosial (Sahid, 2008). Akan nampak dinamika karya sastra sebagai totalitas, sebab proses adopsi mengandaikan terjadinya ciri-ciri transformasi dan regulasi sehingga akan terjadi keseimbangan antara struktur global dengan unsur-unsur yang dianalisis (Piaget, 1973).

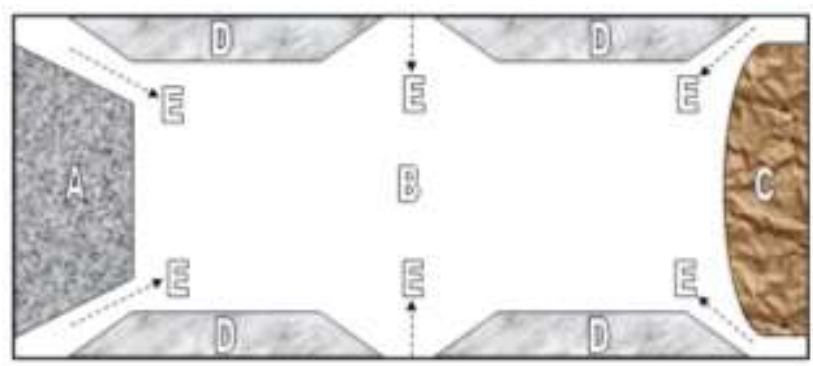

Gambar 1. Rancang ruang pertunjukan 
Keterangan gambar:
A : Mini Stage Area permainan aktor
B : Floor Area permainan actor
C : Mini Stage Area pemusik
D : Area Penonton
E : Lalu lintas pemain

Berikut adalah beberapa tokoh dalam pertunjukan Leng :

\begin{tabular}{|c|c|c|}
\hline No & Tokoh & Keterangan \\
\hline 1 & Baleng & $\begin{array}{l}\text { Aktifis buruh, memiliki } \\
\text { ambisi untuk bisa } \\
\text { berkompetisi di pileg. } \\
\text { Memilih jalan gelap dengan } \\
\text { melakukan pesugihan untuk } \\
\text { mendapatkan kesuksesanya. }\end{array}$ \\
\hline 2 & Neng Ratu & $\begin{array}{l}\text { Istri setia Baleng, } \\
\text { bertentangan dengan jalan } \\
\text { yang ditempuh suaminya. }\end{array}$ \\
\hline 3 & $\begin{array}{l}\text { Nyi } \\
\text { Kembang }\end{array}$ & $\begin{array}{l}\text { Siluman, tempat orang-orang } \\
\text { meminta dan memuja. }\end{array}$ \\
\hline 4 & Sarkim & $\begin{array}{l}\text { Pimpinan Partai tempat } \\
\text { Baleng mencalokan diri } \\
\text { sebagai caleg. }\end{array}$ \\
\hline 5 & Sutet & $\begin{array}{l}\text { Penuntun jalan gelap Baleng } \\
\text { yang membawanya hingga } \\
\text { ke Nyi Kembang. }\end{array}$ \\
\hline 6 & Penari & $\begin{array}{l}\text { Penari desa yang wajahnya } \\
\text { mirip dengan Ratu, jatuh } \\
\text { cinta dengan Baleng dan } \\
\text { begitu sebaliknya. }\end{array}$ \\
\hline 7 & Pepeng & Orang Gila \\
\hline
\end{tabular}

Tabel 2. Tokoh-tokoh dalam naskah Leng

\section{Simpulan}

Penciptaan teater dengan judul Legislatif Celeng adalah perancangan pertunjukan teater degan tahapan penciptaan naskah disertai konsep pertunjukannya. Kerja kreatif ini merupakan kritik terhadap prilaku jahat para calon anggota legislatif yang menggunakan kekuatan uang demi memuluskan cita-citanya menjadi anggota DPR, DPRD, maupun DPD. Siasat Money politic kerap dilakukan oleh calon legislator dengan mengiming-imingi pemilih agar memberikan hak suaranya dengan imbalan uang. Krisis moral para calon anggota legislatif yang terjadi di Negara ini telah mendorong prilaku buruk untuk memanfaatkan masyarakat miskin dengan suap money politic tanpa memperdulikan hukum dan nilai-nilai yang ada di masyarakat. Calon wakil rakyat yang seharusnya memprakrikan cara-cara halal dalam proses demokrasi justru sebagian dari mereka malah kerap membuat intrik untuk menghalalkan segala cara demi nafsu jabatan

Naskah drama Tengul karya Arifin C Noer telah menginspirasi terciptanya naskah dan perancangan pertunjukan ini. Kesamaan nasib antara Korep dalam naskah Tengul dan Baleng dalam naskah LENG adalah sama-sama mengorbankan keyakinannya dengan cara mengabdi pada siluman demi mendapatkan nafsu duniawinya. Namun perbedaan dari keduanya adalah situasi jaman, dimana Tengul adalah pergelutan kemskinan di jaman judi togel, sedangkan LENG pergelutan kemiskinan di jaman pemilu. Selain itu akhir dari kisah keduanya pun mengalami perbedaan, dimana Korep berakhir dengan happy ending sedangkan Baleng berakhir dengan tragis.

Metode psikologi seni Graham Wallace telah membantu Tahapan proses penyusunan perancangan ini dengan sempurna. Melalui empat tahapan penting, yakni; (a) preparation (persiapan), (b) incubation (inkubasi), (c) illumination (iluminasi), dan (d) verification (verifikasi). Melalui tahapan-tahapan itulah maka tercipta sebuah naskah drama beserta perancangannya yang berjudul Legislatif Celeng. Tokoh-tokoh yang terdapat dalamnya merupakan hasil dari tahapan preparation, dimana kumpulan sumber berupa berita-berita diolah dan didistorsi sehingga memunculkan tokoh-tokoh yang 
unik. Melalui sumber-sumber itu pula alur atau plot naskah menemukan arahnya. Pada tahapan illumination proses kreatif semakin diperkaya dengan unsur-unsur yang lain, berbagai pertimbangan dipadukan sehingga menghasilkan sebuah karya yang sesuai dengan kebutuhan.

\section{Daftar Pustaka}

Anirun, S. (1983). Masa depan teater Indonesia. Bandung: Granesia.

Anirun, S. (2001). Menjadi Sutradara. Bandung: STSI Press.

Anwar, C. (2005). Drama, bentuk dan gaya aliran. Yogyakarta: Elkaphi.

Damajanti, I. (2006). Psikologi Seni. Bandung: Kiblat Buku Utama.

Harymawan, RMA. (1988). Dramaturgi. Bandung: PT. Remaja Rosdakarya.

Bahari, N. (2008). Kritik Seni. Yogyakarta: Pustaka Pelajar.

Nurgiyantoro, B. (1995). Teori Pengkajian Fiksi. Yogyakarta: Gadjah Mada University press.

Susanto, M. (2012). Diksi Rupa, Kumpulan istilah dan gerakan seni rupa. Yogyakarta: DictiLab. 